Vol. 5, No. 2 | July - December 2021

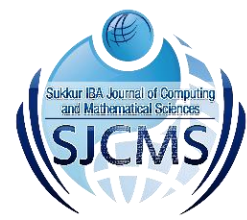

\title{
Testing Salience Model on Work Family Interface: A Regression Analysis
}

\author{
Shumaila Arslan ${ }^{1}$, Muhammad Farhan Tabassum ${ }^{2}$, Muhammad Memon ${ }^{1}$
}

\begin{abstract}
:
The simultaneous arrangement of home and work life is important for all. Many who work at home, however, face difficulties in maintaining their work and domestic relations balance, since both fields are mixed together on a single roof. As telecom technology progresses, the possibilities of working from home have been improved. Discussed the effects of working athome solutions on the quality of work life of the individual. The current research examined in a sample of service workers from Pakistan an extended version of the differential salience model and a related salience model. The results of this study provide some support for the model in a variety of cultural and domestic settings; however, they reveal that domain resources and requirements vary across cultures and households as well. Strong job demands and the present situation of COVID-19 represent primarily technically the work-to-home interference (WtHI). Traveling tools have been identical in terms of reducing the WtHI and work-to-home enhancement (WtHE). WtHE was expected to be more likely because of the activation of personnel services. However, testing one's work had no big influence on WtHE. Moreover, unlike the theoretical model, restriction requirements at the interfaces between work and family have been found to be differential, not comparatively significant.
\end{abstract}

Keywords: work demands, work-to-home interference, work-to-home enrichment, work family interface

\section{Introduction}

Increasing participation of women in the workforce, globalization, and flexible working patterns has led to a growing sense of strain in the workplace, the pressure and the everincreasing conflict between work and personal life [1]. Thus, the work-family interface studies (WFI), which have mainly examined the causes and implications of family-work conflict, are always overwhelmed by a conflicting viewpoint. The WFI discussed the causes and effects of conflicts between work and private life. Aspects of the work and family domains might interact in a variety of ways. Research has recently focused on a more constructive WFI approach by examining the relevant aspects of multi-role participation such as WFI or facilitation [2].

As a result, the work-family interface is better understood when both viewpoints are considered. Negative and optimistic WtHI centered on the effect in this line of research on the family domain in cognitive assessments of the working field. The view of conflict and enhancement between work and family (WFC/E) is gathered from the measurement of its effect, its resources and its work and family roles results. The patterns of association between resources and demands on the one hand are nuanced and not instantly obvious,

\footnotetext{
${ }^{1}$ Institute of Business Administration, University of Sindh, Jamshoro, Pakistan

${ }^{2}$ Department of Sports Sciences \& Physical Education, Faculty of Allied Health Sciences, University of Lahore. Lahore, 54000, Pakistan. Corresponding Author: [mshumailas@yahoo.com] SJCMS | P-ISSN: 2520-0755| E-ISSN: 2522-3003 | Vol. 5 No. 2 July - December 2021
} 
but enrichment and conflict on the other. For example, it can increase work resources and offset job demands in order to avoid WFI conflicts [3]? Voydanoff is known as integrated model, involves a differentiating family conflict and facilitation, work-related approach to work, while the border-related services are needed to depict similar connections with facilitation and conflict. To analyze an integrated model of demands and resources and the WFI, "differential output vs. comparable output" model has been used [3].

The latest literature is extended in a variety of ways. Firstly, only a sample of workers in the United States was checked on Voydanoff's model [3]. In order to draw firm conclusions, the theoretical models can be evaluated in various national/cultural settings. Although Voydanoff [3] found support for its model in theory, empirical findings created some inconsistencies with its theoretical model. More empirical tests are therefore necessary to evaluate the utility of the model further. Secondly, the original model of "different salience versus comparable salience" [3] is expanded to include domain requirements and resources and border resources by also incorporating domain-wide demands. In a later article, boundary demands were proposed [4]. Like border services, border demands are supposed to be compared by prominent to negative and positive WtHI. However, in an applied study model, this has not been empirically checked yet. Thirdly, we have provided initial empirical evidence of effective labor-to-home intervention in the context of Pakistan. Whereas in the Pakistani samples there has been substantial empirical evidence of the conflict perspective and its negative effect on employee well-being, WFI's positive view in work-family research in Pakistan has so far been ignored [5]. Some recent applications of similar work-family interface model are reported in [6-10]

After a significant spike in the 3rd wave, touching the record levels of $+/-200$ deaths/day in end of April, the COVID-19 situation in Pakistan is currently going through a mild decrease. Following the recent slowdown in COVID incidence and death figures due to the 3rd wave, the government has announced partial lifting of some social restrictions: complete lockdown on all commercial activities in all the larger cities from 2 days a week to 1 day; lifting of ban on local tourism subject to vaccination; non-contact sports activities allowed; restaurants to open for outside dining (incl. home delivery, takeaway); 50\% work from home policy relaxed [11].

Initially, a brief overview is given of the theoretical context of the participating buildings. A series of hypotheses are established and tested, is grounded on the differential salience versus the comparable salience mode. Finally, the findings are addressed as well as the consequences, drawbacks and recommendations for future studies.

\section{Theoretical framework}

\subsection{The work-family interface}

In empirical research in the WFI two competing theoretical viewpoints were used to describe the effects of the multiple life functions. Both are the case of scarcity and the argument for improved function theory. An individual has a small number of resources and energy, according to the scarcity claim. By encouraging various roles in life, as professional and personal life, it means fighting for these resources, leading to workfamily conflict experiences. Few studies have evaluated work/home interference as a multidimensional system, however [12]. Those research that analyzes the three dimensions of WtHI separately finds no difference in working history [13].

Sociological theories of 1970s which are based upon the work and the case for enhanced life indicate that having busy in diverse pursuits will give social and economic capital and thus be of benefit to persons. In a thirtyyear study [14] the long-term positive influence of multiple positions on women's health and social inclusion has been demonstrated. While there is convincing proof that numerous roles can be advantageous, work-family research is controlled by a 
conflicting viewpoint that is based on the shortage of claims of the theory of roles. Just recently, family students have developed a set of constructions that control the positive side of the work-family interface, as positive spillover, enhancer and facilitation [2].

This study focuses on WtHE, which is described as "the excess of the quality of life in the other role that experiences in one role improve" [2]. Work/home enrichment is a bidirectional and multidimensional system similar to work/family conflict: work exposure can develop the excellence of family and private life $\mathrm{WtHE}$ and family and private experience can improve the quality of work. Two ways of enhancing the other function are: resources as material resources, expertise and society capital increases quality and performance in another area. WtHE is comprised of three dimensions: affective developmental, capital and enhancement, while HtWE depends on a small difference between developmental, affective, and efficiency-based enhancement.

\subsection{Differential salience vs. comparable salience model}

By building the work-house intervention model of dual-process [3] an integrative demand and resource structure were proposed, incorporating all the theoretical arguments. The "differential salience versus the comparable salience" model indicates that the demands and resources of the internal domain work vary from the negative and the positive interference from work and family, while the boundary resources remain comparatively essential to positive and negative interference of the family and work.

Domain job requirements denote social or organizational and physical facets of a position which involve sustained psychological and physical efforts and thus associated with unique physical and mental costs. In keeping with the scarcity claim, internal work demands restrict employees' ability to handle non-work domain obligations effectively, consequently leading to undesirable and negative interferences with their work-to-family. Timebased pressures, as extended working hours and spare time, can limit the available time for people to live in their families and also develops hardships for them to accomplish responsibilities of family. strain-based work involves a person's willingness or readiness to fulfill family roles responsibilities which can contribute to tension and stress experiences [15].

Domain workplace tools relate to elements of your job that work to achieve job goals, minimize costs linked to job requirements, or encourage personal growth and development. Jobs tools may be either inherent to the task or within the workplace. The improvement argument of multiple life roles encouraging workers to act better in the family domain, allows involvement in work to produce certain domain resources including talents, abilities, certain attitudes and social support. Psychological benefits and awards, such as inspiration, success and self-esteem, can also reach out from work to family and improve constructive interference with family work.

However, domain demand and resources are features of the workplace environment that reduce or improve employee capacity to fulfill family-related responsibilities, border requirements and resources deal specifically with the relation between the workplace and the family/home. The Instances of boundary demands are unsupportive family-work culture or a home-work culture. Examples of borderspreading tools are assistance from managers and colleagues and agreeable working measures. Border-crossing resources, according to the theoretical model, are able to both minimize negative family-to-work intrusion or interference and increase positive family-to-work interference through mechanisms that improve employees' ability to handle work-to-family boundaries.

We have developed a series of hype-sets on the basis of [3] integrative structure for a various domain requests and resources, border requirements and resources and work-for-thehome intervention and home enrichment. The research variables and hypothesized relations are summoned in Figure 1. 


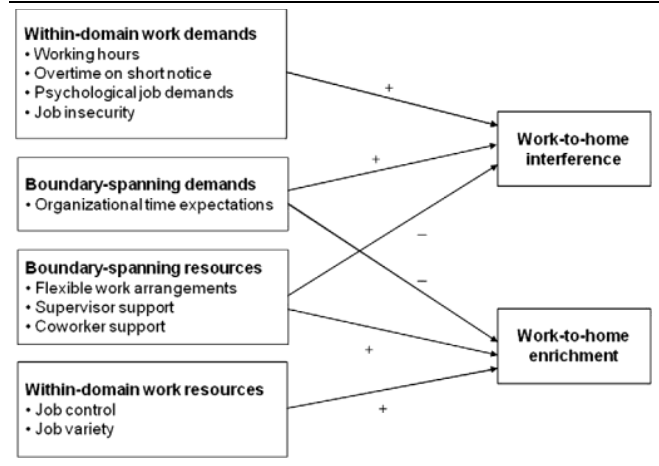

Fig. 1. Research model adapted from [3]

\section{Hypotheses}

\subsection{Work demands}

A prominent topic in the field of family research was the negative effect of extensive working hours and extra time of duty on workers' ability to efficiently handle their work-family interface. The amount of negative work-to-home intervention supposed by the person increases in proportion to the number of hours spent at work according to the logical model of work-family conflict. A variety of observational studies that indicate a positive connection between work and working hours are behind this claim. This argument is backed by Furthermore, short-term overtime conditions explicitly restrict the freedom of workers to fulfill workplaces and increase negative intrusion from work to private life [3].

Hypothesis \# 1: Working hours will be positively related to WtHI.

Hypothesis \# 2: Overtime on short notice will be positively related to $\mathrm{WtHI}$.

The requests for therapeutic work relate to stressors specifically linked to the task and workload. For example, a heavy workload and competing demand for employment can generate a pressure that penetrates private lives and increases WtHI's experience.

Hypothesis \# 3: Psychological job demands will be positively related to WtHI.

Global rivalry and restructuring have intensified the employee's feelings of vulnerability and are well known in the literature as its harmful influence on workers' jobs and well-being. This research stresses on the assumed job insecurity and in assurance that refers to the fear or concern of a person about the future of work.

Hypothesis \# 4: Perceived job insecurity will be positively related to WtHI.

\subsection{Work resources}

Work resources may be connected to the job or to the wider work environment. In this paper, we concentrate on two kinds of intrinsic work tools, namely job management and the variety of skills/work. Employment management is about how an employee knows him/her will control when, where and how his/her work is done. The diversity of employment and abilities mentions the skills and imagination, a worker requires versatility of workers to choose their skills at work.

Hypothesis \# 5: Job control will be positively related to WtHE.

Hypothesis \# 6: Job variety will be positively related to WtHE.

\subsection{Boundary-spanning demands and resources}

Supporting domestic work and domestic work rules or policies are essential components of a work environment that is familiar [16]. Family work culture refers to the ideals and principles behind the preference of work over family and vice versa in organizing the work culture it refers to the universal values. Voydanoff [3] claims that a culture of a familybacked company legitimizes the unworked needs of workers at work and efforts to respond to private obligations. This will reduce the burden on workers and their distress in connection with disputes between professional and private and upsurge the positive spillover of jobs and the non-labor domain.

As the culture of Work and family is characterized in family literature as a multidimensional construct with expectations of time, negative job outcomes, supervisor and co-worker support that encompasses the main areas of work-family culture. With regard to 
the different aspects of family work culture [4] the categorization of border demands and resources, organizational time requirements can better be interpreted as border-related demands, whereas manager and coworkers' aid is border-related resources.

Hypothesis \# 7: Organizational time expectations will be (a) positively related to $\mathrm{WtHI}$ and (b) negatively related to WtHE.

Hypothesis \# 8: Supervisor support will be (a) negatively related to $\mathrm{WtHI}$ and $(b)$ positively related to $\mathrm{WtHE}$.

Hypothesis \# 9: Co-worker support will be (a) negatively related to $\mathrm{WtHI}$ and $(b)$ positively related to WtHE.

The reaction and response to growing job and household requirements of workers flexible working policies (FWAs) have been adopted by many businessmen as telework, shortened work weeks flextime, Flexible working agreements permit workers to handle both their jobs and their non-work duties more efficiently, allowing employees temporary or room flexibility on their work site.

Hypothesis \# 10. Use of flexible work arrangements will be (a) negatively related to $\mathrm{WtHI}$ and $(b)$ positively related to WtHE.

\section{Methodology}

\subsection{Procedure and participants}

The data were obtained from employees in services in three Lahore University of Lahore, Lahore Garrison University and Management University institutions. In an online questionnaire, we collected information. The questionnaire could be completed during working hours by all participants. A total of 500 questionnaires have been circulated to different levels of hierarchy. Returned 231 questionnaires (for an overall response rate of 46 percent).

$39 \%$ of the participants were male and $61 \%$ were female. The mean age of the participants was 34.3. $44 \%$ had married or lived in partnership, and the remainders were individual.

The participants were asked how many hours they work each week, including paid or unpaid hours, but they don't take into account travel time.

\subsection{Psychological job demands}

In order to assess the psychological demands at work [17], 5 items have been taken from the Swedish Demand-Control-Support Questionnaire (DCSQ). The ratings for each object were 4 -point $(1=$ never to $4=$ always $)$

Job insecurity: Four Likert-scale items were used to assess work insecurity perceived $(1=$ strongly disagree to $5=$ strongly agree $)$ [18].

Job control: Two items from the decisionmaking authority level of Swedish DCSQ [17], were evaluated for job management, each item being scored on a 4 -point scale $(1=$ never to $4=$ always).

Job variety: The Swedish DemandControl-Support Questionnaire (DCSQ) [17] used the three elements on the discretionary range to evaluate the variety of employment. Answers were given on a 4-point scale ( $1=$ never; 4 = always).

Work-family culture: Three elements each were used for measuring the dimensions of perceptions of organizational time and support from employees. The supervisor help calculates two things. Several things were extracted from the measurement of family culture and multi-dimensional work [19]. A five-point Likert scale reply was received. (1 = strongly disagree to $5=$ strongly agree).

FWA use: Participants were asked whether they had worked for flextime, telework or a shortened workweek for the last 12 months. It was calculated that a dummy variable with 0 showed that no flexible work structures were implemented, while one proposed that one policy at least had been adopted in the last 12 months. 


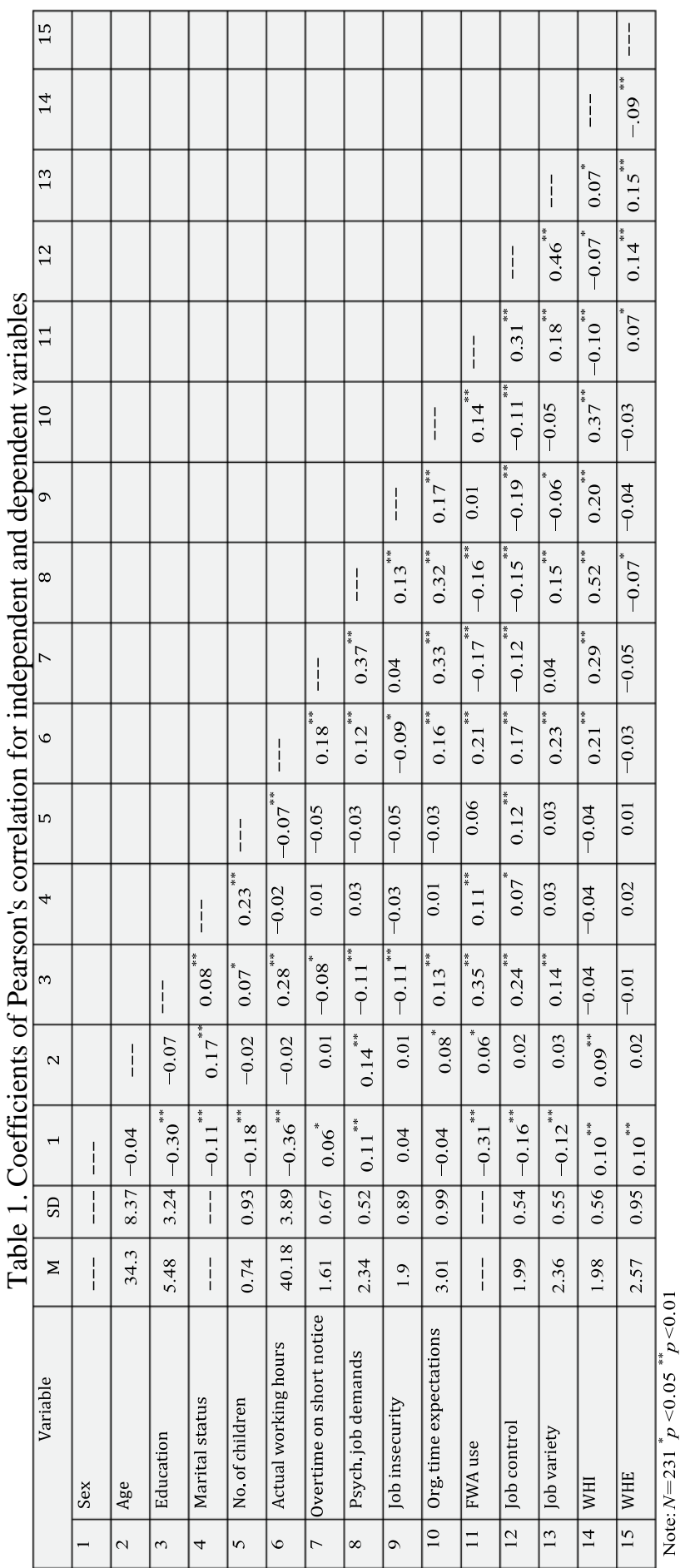


Shumaila Arslan (et al.), Testing Salience Model on Work Family Interface: A Regression Analysis

(pp. $14-24)$

Table 2. Regression analysis of work-to-home interference

\begin{tabular}{|c|c|c|c|c|c|}
\hline \multirow{2}{*}{$\begin{array}{c}\text { Variables and statistics } \\
\text { Controls }\end{array}$} & \multicolumn{5}{|c|}{ Standardized betas } \\
\hline & Model 1 & Model 2 & Model 3 & Model 4 & Model 5 \\
\hline Female sex & 0.04 & $0.12 * *$ & $0.12 * *$ & $0.11 * *$ & $0.11 * *$ \\
\hline Age & $0.07 *$ & 0.05 & 0.05 & 0.05 & 0.05 \\
\hline Education & 0.02 & 0.01 & 0.01 & -0.01 & -0.01 \\
\hline Married & -0.04 & -0.03 & -0.03 & -0.02 & -0.01 \\
\hline \multicolumn{6}{|l|}{ Work demands } \\
\hline Working hours & & $0.18 * *$ & $0.19 * *$ & $0.18 * *$ & $0.17 * *$ \\
\hline Overtime on short notice & & $0.11 * *$ & $0.09 * *$ & 0.04 & 0.02 \\
\hline Psych. job demands & & $0.41 * *$ & $0.41 * *$ & $0.38 * *$ & $0.37 * *$ \\
\hline Job insecurity & & $0.19 * *$ & $0.17 * *$ & $0.15 * *$ & $0.15 * *$ \\
\hline \multicolumn{6}{|l|}{ Work resources } \\
\hline Job control & & & 0.00 & 0.01 & 0.04 \\
\hline Job variety & & & -0.03 & -0.02 & -0.01 \\
\hline \multicolumn{6}{|l|}{ Boundary - spanning demands } \\
\hline Org. time expectations & & & & $0.18 * *$ & $0.17 * *$ \\
\hline \multicolumn{6}{|l|}{ Boundary - spanning resources } \\
\hline Supervisor support & & & & & $-0.08 * *$ \\
\hline Co - Supervisor support & & & & & $-0.06 *$ \\
\hline FWA use & & & & & $-0.08 *$ \\
\hline $\mathrm{F}$ & $7.24 * *$ & $38.00 * *$ & $32.65 * *$ & $32.95 * *$ & $29.53 * *$ \\
\hline $\mathrm{R}^{2}$ & 0.06 & 0.34 & 0.34 & 0.36 & 0.37 \\
\hline Adjusted $\mathrm{R}^{2}$ & 0.05 & 0.33 & 0.33 & 0.34 & 0.36 \\
\hline Change in $\mathrm{R}^{2}$ & & 0.28 & 0.00 & 0.01 & 0.02 \\
\hline
\end{tabular}

Note: $\mathrm{N}=231 * \mathrm{p}<0.05 * \mathrm{p}<<0.01$

Table 3. Regression analysis of work-to-home enrichment

\begin{tabular}{|c|c|c|c|c|c|}
\hline \multirow{2}{*}{$\begin{array}{c}\text { Variables and statistics } \\
\text { Controls } \\
\end{array}$} & \multicolumn{5}{|c|}{ Standardized betas } \\
\hline & Model 1 & Model 2 & Model 3 & Model 4 & Model 5 \\
\hline Female sex & $0.17 * *$ & $0.15 * *$ & $0.16 * *$ & $0.15 * *$ & $0.15 * *$ \\
\hline Age & 0.047 & 0.04 & 0.04 & 0.04 & 0.05 \\
\hline Education & -0.03 & -0.03 & -0.04 & -0.04 & -0.04 \\
\hline Married & 0.03 & 0.03 & 0.03 & 0.03 & 0.02 \\
\hline \multicolumn{6}{|l|}{ Work demands } \\
\hline \begin{tabular}{|l|} 
Working hours \\
\end{tabular} & & -0.03 & -0.04 & -0.04 & -0.03 \\
\hline Overtime on short notice & & -0.05 & -0.05 & -0.05 & -0.03 \\
\hline Psych. job demands & & -0.05 & -0.07 & -0.07 & -0.06 \\
\hline Job insecurity & & -0.03 & -0.02 & -0.02 & -0.02 \\
\hline \multicolumn{6}{|l|}{ Work resources } \\
\hline Job control & & & 0.06 & 0.06 & 0.02 \\
\hline Job variety & & & $0.14 * *$ & $0.14 * *$ & $0.12 * *$ \\
\hline \multicolumn{6}{|l|}{ Boundary - spanning demands } \\
\hline Org. time expectations & & & & 0.03 & 0.02 \\
\hline \multicolumn{6}{|l|}{ Boundary - spanning resources } \\
\hline Supervisor support & & & & & $0.14 * *$ \\
\hline Co - supervisor support & & & & & $0.13 * *$ \\
\hline FWA use & & & & & $0.14 *$ \\
\hline $\mathrm{F}$ & $4.08 * *$ & $3.47 * *$ & $4.66 * *$ & $4.39 * *$ & $5.81 * *$ \\
\hline
\end{tabular}

Sukkur IBA Journal of Computing and Mathematical Science - SJCMS | Vol. 5 No. 2 July - Dec 2021 


\begin{tabular}{|l|l|l|l|l|l|}
\hline $\mathrm{R}^{2}$ & 0.04 & 0.05 & 0.07 & 0.07 & 0.11 \\
\hline Adjusted $\mathrm{R}^{2}$ & 0.03 & 0.03 & 0.05 & 0.05 & 0.09 \\
\hline Change in $\mathrm{R}^{2}$ & & 0.00 & 0.02 & 0.00 & 0.04 \\
\hline
\end{tabular}

Note: $\mathrm{N}=231 * \mathrm{p}<0.05 * * \mathrm{p}<0.01$

Work-to-home interference: The WtHI evaluation was conducted using three elements from the SWING Work-Home Interaction Survey Nijmegen [20]. Each object has been classified on a scale of 4 points $(1=$ never to 4 = always).

Work-to-home enrichment: The developmental factor of WtHE has been measured through three elements taken from the enrichment scale of the work-family [21]. A five-point Likert scale was followed (1 = strongly disagree to $5=$ strongly agree).

Control variables: The statistical analysis used the control variables of sex, age, educational level, educational status, marital status and number of children. Sex is $0=$ male, $1=$ female, marital status is $0=$ not married, 1 $=$ married. Sex is married $0=$ not married. The level of education was measured by requiring the participants to show in a 7-point scale the highest level they had attained.

\section{Results and Discussions}

The coefficients, means and normal variants for Pearson's correlations for all variables have been shown in Table 1. The trial hypotheses had been tested with ordinary least square regression analyzes. The equation contained demands for work, sequential control variables, work capitals and boundary demand and resources. Dummy variables were used to analyze further socio-demographic variables. Table 2 and Table 3 display the results for $\mathrm{WtHI}$ and $\mathrm{WtHE}$.

Table 2 showed that many requests from inside the domain were linked positively to negative interference with working hours ( $ß$

The latter paper researched the extended sampling in Pakistan as servicing workers for the "differential salience versus similar salience model" [3]. The model implies that
$=.18)$, Overtime on short notice $(ß=.11)$, psych. job demand $(\beta=.41)$ and to job insecurity ( $\mathrm{s}=0.19$ ) (Model 2). There was no influence on coefficients by incorporating job tools. However, when border-related demands were made, extra time was a significant predictor of WtHI in the short term. Hypothesis 2 was not thus supported, although our evidence supported Hypotheses 1, 3 and 4. In line with the forecasts, expectations of organizational time in the case of $\mathrm{WtHI}(\beta=$ 0.18 ), supporting hypothesis $7 \mathrm{a}$, are important and optimistic. The WtHI (assistant supervisor's help $(\beta=-.08)$; co-superstor assistance $(\beta=-.08)$; FWA use $(\beta=-.08))$ is strongly and adversely linked to multiple boundary resources. So, the $8 \mathrm{a}, 9 \mathrm{a}$ and $10 \mathrm{a}$ hypotheses were endorsed. with our Figure 1 theoretical model, there were no significant interactions between within the domain working resources and $\mathrm{WtHI}$.

Table 3 shows that demands for work were not substantially associated with our theoretical model WtHE (Model 5). The use of flexible work arrangements was substantially connected to WtHE in many border-spanning tools, supervisor support $(\beta=.14)$, and cosupervisor support $(\beta=13)$ in addition to the application of flexible work arrangements $(\beta=.14)$, thus supporting Hypothesis $8 \mathrm{~b}, 9 \mathrm{~b}$ and $10 \mathrm{~b}$. In comparison to the forecasts, WtHE did not substantially apply to border-related requirements. Hypothesis $7 \mathrm{a}$ has therefore not been endorsed. In the work tools, WtHE (model 5), supporting hypothesis 6, was linked significantly and positively only by the variety of work $(\beta=.14)$. Contrary to Hypothesis 5 , a substantial association with WtHE has not been seen in the job regulation.

demands for work and resources are different from the others, while restricting demands and resources are equally important in relation to both definitions. It partly supports the extended model of salience that results in some findings which vary from [3] theoretical and past 
empirical findings. This term has shown significant and positive correlations with WtHI between requirements such as hours of work, demands for mental work, and job insecurity. Overtime for short notices was not substantially connected to WtHI contrary to forecasts and [3] findings. The relationship was negligible until demands of organizational time were taken in consideration, which suggested that overtime could serve as a mediator in the short term. A request to stay at work for longer periods in a short period seems to give the impression that a time-consuming organization has no difference for non-work and private life, apart from work. These insights form a significant share of a working/family culture in the organization and have been got to negatively impair the emotional state of employees in their personal lives. According to [3] The partnership was negligible before the organizational time demands were addressed, which indicated the possible short-term mediation of overtime. A proposal for longer periods of stay at work in a short period seems to suggest that the timeconsuming organization, aside from work, does not value work and private life. Such experiences are an important part of a work/family culture of an enterprise and have revealed their own emotions. Van Echtelt, Glebbeek, and Lindenberg [22], for example, staff working in high-level organizations worked far longer than they wanted location control and time ("autonomy paradox"). The focus was not on clock time but on the task and project completion in these working environments. Employees were so involved that they spent time on work completing their work tasks and projects. Although they were formally entitled to adjust the working time, there was no reduction in the working environment. Contrary to the view of the WTHI reduced resources for scheduling power and work autonomy, Schieman and Glavin [23] Take responsibility for "blurring the lines between work and home. You may demonstrate that the blurring of the role of the homework is related to an increased degree of conflicts between work and home. In a similar vein, [24] employees with high level of authority and freedom of choice were more likely to be adversely affected from home to work.

\section{Conclusion and implication}

The theoretical implications of the current research are numerous. The research first tested the differential salience against the corresponding salience model in a separate national sense [3] Our findings from a Pakistan-wide sample of service employees nevertheless suggest the variations between the WtHI and WtHE border-wide requirements. Our review confirms that limited resources need to be defined as technically distinct from WtHI and WtHE-related domainspecific resources. In general, it gives some initial empirical proof of Pakistan's history of job-to-home enrichment.

From an applied perspective, the study shows that organizations designed to reduce the friction among workers crossed the simple drop-in labor requirements and created a satisfactory working atmosphere in which the family enjoys its wellbeing. Organizations have a specific benefit from investments in staff-based facilities, as two advantages are found by managers and partners and flexible job arrangements, less negative participation from work in the home and greater enhancement from homework.

'Family-friendly' work and work-life balance is important for peace and performance. Numerous limitations of the research design must be considered during the analysis of the findings of this report. This study concerns workers in the service sector in order to prevent a wider population from reaching the conclusions. The analysis of a wider range of industries will help with future studies. The second disadvantage of this study is that the transversality of non-experiments is not definitive in causes. Although the study results conform greatly to the supposed causal model in Figure 1, rival interpretations of the relationships found cannot be ruled out. In future experimental study designs and longitudinal studies must specifically identify the directions of such connections. 


\section{REFERENCES}

[1] Green, F., Demanding work: The paradox of job quality in the affluent economy. 2006: Princeton University Press.

[2] Greenhaus, J.H. and G.N. Powell, When work and family are allies: A theory of work-family enrichment. Academy of management review, 2006. 31(1): p. 7292.

[3] Voydanoff, P., The effects of work demands and resources on work-to-family conflict and facilitation. Journal of Marriage and family, 2004. 66(2): p. 398412.

[4] Voydanoff, P., Toward a conceptualization of perceived workfamily fit and balance: A demands and resources approach. Journal of marriage and family, 2005. 67(4): p. 822-836.

[5] Wiese, B.S., Wahrgenommene familienunterstützende

Unternehmenskultur: Beziehungen zur allgemeinen und arbeitsbezogenen Befindlichkeit. Wirtschaftspsychologie, 2004: p. 72-85

[6] Nielsen, J.D., et al., The moderating role of calling in the work-family interface: Buffering and substitution effects on employee satisfaction. Journal of Organizational Behavior, 2020. 41(7): p. 622-637.

[7] Dinh, H., et al., Is self-employment a good option? Gender, parents and the workfamily interface. Sex Roles, 2021. 84(11): p. 731-746.

[8] Li, Y., Antecedents of the Positive WorkFamily Interface-A Meta-Analysis. 2017, Université d'Ottawa/University of Ottawa.

[9] Zhang, C., B.J. Dik, and Z. Dong, Living a Calling and Work-Family Interface: A Latent Profile Analysis. Journal of Career Assessment, 2021: 10690727211006701

[10] Hirschi, A., et al., Action Regulation at the Work-Family Interface: Nomological Network and Work-Family Consequences. Journal of Business and Psychology, 2021: p. 1-19.

[11] trade, f., CORONAVIRUS - The situation in Pakistan. 2021.

[12] Eby, L.T., et al., Work and family research in IO/OB: Content analysis and review of the literature (1980-2002). Journal of vocational behavior, 2005. 66(1): p. 124197.

[13] Chen, Z., G.N. Powell, and J.H. Greenhaus, Work-to-family conflict, positive spillover, and boundary management: A person-environment fit approach. Journal of vocational behavior, 2009. 74(1): p. 82-93.

[14] Moen, P., D. Dempster-McClain, and R.M. Williams Jr, Successful aging: A life-course perspective on women's multiple roles and health. American Journal of Sociology, 1992. 97(6): p. 1612-1638.

[15] Frone, M.R., J.K. Yardley, and K.S. Markel, Developing and testing an integrative model of the work-family interface. Journal of vocational behavior, 1997. 50(2): p. 145-167.

[16] Allen, T.D., Family-supportive work environments: The role of organizational perceptions. Journal of vocational behavior, 2001. 58(3): p. 414-435.

[17] Sanne, B., et al., The Swedish DemandControl-Support Questionnaire (DCSQ): Factor structure, item analyses, and internal consistency in a large population. Scandinavian journal of public health, 2005. 33(3): p. 166-174.

[18] Sverke, M., Job insecurity and union membership: European unions in the wake of flexible production. 2004: Peter Lang.

[19] Dikkers, J., et al., Relations among workhome culture, the utilization of workhome arrangements, and work-home interference. International Journal of Stress Management, 2004. 11(4): p. 323.

[20] Wagena, E. and S. Geurts, SWING. Ontwikkeling en validering van de" Survey Werk-thuis InterferentieNijmegen.". Gedrag \& Gezondheid: Tijdschrift voor Psychologie en Gezondheid, 2000.

[21] Carlson, D.S., et al., Measuring the positive side of the work-family interface: Development and validation of a workfamily enrichment scale. Journal of vocational behavior, 2006. 68(1): p. 131164.

[22] Van Echtelt, P.E., A.C. Glebbeek, and S.M. Lindenberg, The new lumpiness of work: explaining the mismatch between actual and preferred working hours. Work, employment and society, 2006. 20(3): p. 493-512.

[23] Schieman, S. and P. Glavin, Trouble at the border?: Gender, flexibility at work, and the work-home interface. Social Problems, 2008. 55(4): p. 590-611.

[24] Schieman, S., P. Glavin, and M.A. Milkie, When work interferes with life: Worknonwork interference and the influence of 
Shumaila Arslan (et al.), Testing Salience Model on Work Family Interface: A Regression Analysis

(pp. $14-24)$

work-related demands and resources.

American Sociological Review, 2009.

74(6): p. 966-988.

Sukkur IBA Journal of Computing and Mathematical Science - SJCMS | Vol. 5 No. 2 July - Dec 2021 